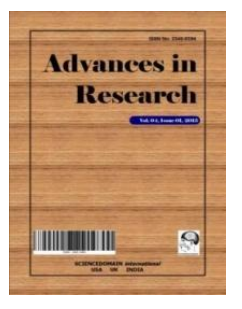

\title{
Advances in Research
}

10(3): 1-9, 2017; Article no.AIR.34595

ISSN: 2348-0394, NLM ID: 101666096

\section{Radiation Pattern of a Circularly Polarized Microstrip Short Backfire Antenna}

\author{
Kawa Abdoula ${ }^{1 *}$ \\ ${ }^{1}$ Department of Communication Engineering, Technical University of Varna, Studentska Str. 1, \\ 9010 Varna, Bulgaria.
}

Author's contribution

The sole author designed, analyzed and interpreted and prepared the manuscript.

Article Information

DOI: $10.9734 / A I R / 2017 / 34595$

Editor(s):

(1) Omveer Singh, Electrical Engineering Department, School of Engineering, Gautam Buddha University, India.

Reviewers:

(1) Anuj Kumar Goel, Maharishi Markandeshwar University, India.

(2) A. Ayeshamariam, Khadir Mohideen College, India.

(3) Roman Kubacki, Military University of Technology, Poland.

Complete Peer review History: http://www.sciencedomain.org/review-history/19814

Original Research Article

Received $1^{\text {st }}$ June 2017

Accepted $28^{\text {th }}$ June 2017

Published $3^{\text {rd }}$ July 2017

\begin{abstract}
A circularly polarized microstrip short backfire antenna (CPMSBA) with one ring corrugated rim, using aperture coupled feed method is proposed in this paper. The antenna is designed to operate in KU-band. The simulation results verify the circular polarization. The impedance bandwidth is 0.83 $\mathrm{GHz}$. The $\mathrm{CP}$ antenna provides good radiation pattern over the whole frequency range. The axial ratio bandwidth bwAR is $2.96 \%$, the gain is $9.79 \mathrm{dBi}$, directivity is $10.17 \mathrm{dBi}$ and radiation efficiency is $91.62 \%$. The antenna has a compact structure, high electrical and mechanical characteristics, it can be used as a single antenna or as an element of microstrip antenna arrays with various applications in the various communication systems.
\end{abstract}

Keywords: Radiation pattern; aperture coupled microstrip antenna; back radiation; circularly polarized microstrip antenna with one ring; microstrip short backfire antenna.

\section{INTRODUCTION}

Recently there has been a growing demand of microwaves in various applications resulting in an interest to improve antenna performances. Wireless communication systems and instruments like wireless local area networks (WLAN), cellular phones etc. require small size, 
low cost, light weight antennas. The selection of microstrip antenna technology can fulfill these requirements [1-3]. Significant advances in the design of microstrip antennas have been presented over the last decades. Defected ground structure is one of the techniques used to reduce the antenna size [4]. Microstrip patch antennas suffer from several inherent disadvantages of this technology in its pure form, namely, they have small bandwidth and relatively poor radiations efficiency resulting from surface wave excitations and conductor and dielectric losses. Many specialized techniques have been developed to increase the bandwidth of a microstrip antenna. These include either using thick foam substrates along with aperture coupled feeds to avoid the probe reactance limitation, or using capacitive elements to compensate for the probe inductance. Even further increases may be achieved by using configurations that exhibit dual or multiple resonances, including stacked resonators or antennas surrounded by parasitically coupled elements. [5]. Microstrip Backfire Antenna can be used as single antenna can take the place of four or more microstrip radiating elements and provide overall thinning of an array. Circularly polarized antenna is employed to avoid power loss caused by Faraday polarization rotation in satellite communications. [6-9]. The microstrip antennas (MSAs) may be designed for circular polarizations by adjusting their physical dimensions to produce two degenerate orthogonal modes with in the cavity region. This in turn results in the radiation of two orthogonally polarized waves near the broadside direction. Thus, circularly polarized radiation is obtained when two orthogonal modes are excited with equal amplitude and in-phase quadrature [10].

\section{RADIATIONS MECHANISM}

The basic microstrip antenna is consisting of a radiating patch on one side of a dielectric substrate, which has a ground plane of the other side. The microstrip patch and the ground plane together form a resonant cavity (filled with the substrate material). The cavity is lossy, due not only to the material (conductor and dielectric) loss, but also to the (desirable) radiation into space [11].

In Fig. 1. The electromagnetic energy provides by the feed microstrip line passes though rectangular slot into the first resonator formed by patch element and the ground plane. After multiple reflections between the inner walls of the first resonator, a part of this energy radiated directly into the space and other part of this electromagnetic energy penetrates via the short sides of the patch element to the second resonator, formed by the small reflector and ground plane. After multiple reflections between the inner walls of the second resonator, the electromagnetic energy radiated between the short sides of the small reflector and the rim in the broadside of the antenna. The rim reduces the back and side radiations of the proposed antenna.

\section{DESCRIPTION OF THE ANTENNA}

Fig. 1. shows the geometry of the aperture coupled microstrip short backfire antenna (ACMSBFA) The antenna consists of the following elements:

1. Screen 2. Screen Substrate 3. Feed line 4. Feed substrate 5. Ground (D2) 6. Rim 7. Rectangle Cross-Slot 8. Patch 9. Patch substrate 10. Small Reflector (D1) 11. Additional substrate. 12.Small reflector Substrate 13. Additional ring and five substrates as follows: additional substrate AS (Taconic TLX-7: "عrt $=2.6$, tan $\mathrm{t}=$ 0.0019 ); small reflector substrate SRS (Ärlon $A D$ 410: "عrq $=4.1, \tan \_q=0.0030$, the small reflector substrate is realized by two layers with standard thickness of $3.175 \mathrm{~mm}$ ); patch substrate PS (Arlon AD 600: "عrp = 6.15, tan $P=0.0030$ ); feed substrate FS (Arlon AD 600: "عrf $=6.15$, tan $f f=0.0030$ ) and screen substrate SS (Taconic TLX-7: "عrs=2.6, tan_S=0.0019).

\section{DESIGN OF THE ANTENNA}

The linearly polarized (LP) antenna with aperture coupled method is chosen as a prototype, as it is allowing independent optimizations of the both parts of the antenna (feeding and radiations parts).

The transitions of LP to circularly polarization (CP) is done by creation a cross slot (insertions of the second slot $\mathrm{Sl}_{2}$ orthogonal to the first slot $\mathrm{SI}_{1}$ ) and rotation of the microstrip feed line by 45 degrees around the cross slot. The values of the basic dimensions and constructive parameters were determinized by optimizations procedure done by software package CST MWS 2010 and the results were verified with software package HFSS. 


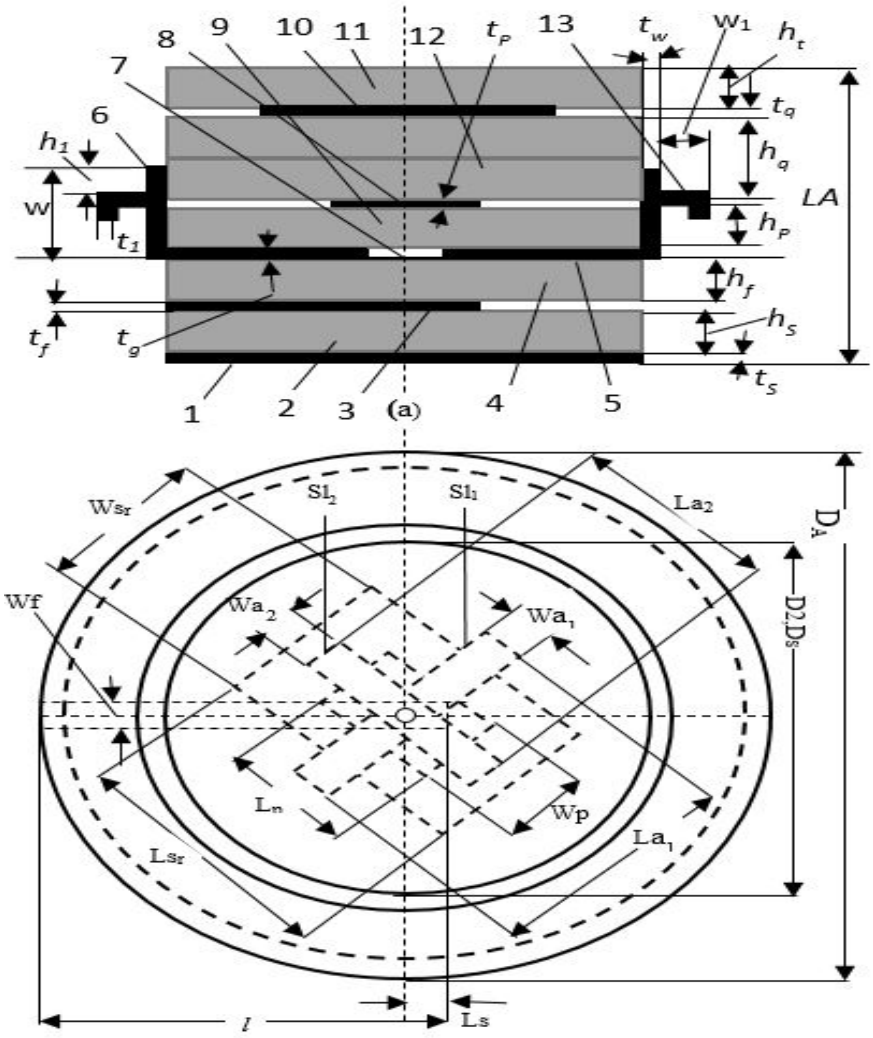

(b)

Fig. 1. Geometry of the antenna

(a) Cross section (b) Front view

14 of the dimensions and constructive such as patch width $W P$, patch length $L P$, cross slot average length $L a$, patch size coefficient $K P$, cross slot size coefficient $K S$, slot 1 length $L a 1$, slot 1 width Wa1, slot 2 length La2, slot 2 width $W$ 22, small reflector length $L s r$, small reflector size coefficient $K 1$, small reflector width $W$ sr, ring width $W 1$, and the matching stub length $L S$ were used in the optimization.

Their number was reduced to 8 using the 6 interrelations to the La1, La2, Wa1, Wa2, WP and Wsr shown in Table 2. The rest of the parameters such as $L P, K 1, K P, K S, L a, L s, L s$, and $W 1$ are optimized independently.

These parameters are investigated in the frequency range $10 \mathrm{GHz}$ to $13.5 \mathrm{GHz}$. The optimum values of these eight parameters are found by several iterations as shown in the Table 2.

The dimensions of the proposed CP antenna are listed in the Table 1, the optimized parameters of the antenna structure are listed in Table 2, and the electrical parameters of the CP antenna are shown in the Table 3.

\section{SIMULATIONS RESULTS}

The simulations of the proposed antenna are carried out by software package CST MWS 2010 and the results were verified with software package HFSS. The parametric analysis was completed and published [12].

Fig. 2a, b and c Shows the radiation pattern at frequency $11.62 \mathrm{GHz}, \varphi=0, \varphi=45$ and $\varphi=90$ degree. Co- polarization radiation pattern or right hand circularly polarization (RHCP) with red line and cross-polarization radiation pattern or left hand circularly polarization (LHCP) with blue dashed. The radiation pattern of the antenna illustrates the distribution of radiated power in the space.it seems from the figure that the CP antenna provides good and stable radiation pattern over the whole frequency range. 
Table 1. Dimensions of the antenna

\begin{tabular}{lll}
\hline Dimensions [mm] & Description \\
\hline D2 & 24 & Big Reflectors inner diameter \\
tg & 0.0175 & Big reflector\& ground thickness \\
L & 13.155 & Antenna length \\
Wsr & 3.30 & Small reflector width \\
W & 7.6825 & Rim width \\
tt & 0.035 & Small reflector thickness \\
tw & 0.5 & Rim thickness \\
Wp & 2.38 & Patch width \\
tp & 0.035 & Patch thickness \\
Wa & 0.45 & Slot1 width=0.1 La1 \\
Wa & 0.40 & Slot2 width=0.1 La2 \\
I & 11.9 & Microstrip feed line length \\
Ls & 1.0 & Stub length \\
Wf & 0.98 & Microstrip feed line width \\
tf & 0.0175 & Microstrip feed line thickness \\
Ds & 24 & Screen diameter \\
ts & 0.035 & Screen thickness \\
ht & 1.58 & Additional substrate thickness \\
hq & 6.35 & Small reflector substrate thickness \\
hp & 1.27 & Patch substrate thickness \\
hf & 0.635 & Feed substrate thickness \\
hs & 3.175 & Screen substrate thickness \\
t1 & 0.5 & Ring thickness \\
h1 & 0.4 & Distance between the upper edge of the peripheral screen and the upper edge \\
& & of the ring \\
\hline
\end{tabular}

Table 2. Optimized parameters of the antenna structure

\begin{tabular}{lll}
\hline Name & Value[mm] & Description \\
\hline Lp & 2.7 & Patch length \\
K1 & 1.08 & Small reflector ratio Lsr/Wsr \\
Kp & 1.06 & Patch Ratio Lp/Wp \\
Ks & 1.10 & Slot Ratio La1/La2 \\
La & 4.1 & Slot length \\
La1 & $\left(2^{*} \mathrm{La} \mathrm{Ks}\right) /(\mathrm{Ks}+1)$ & Aperture 1 length \\
La2 & $2^{*} \mathrm{La} /(\mathrm{Ks}+1)$ & Aperture 2 length \\
Ls & 0.9 & Stub length \\
Lsr & 4.1 & Small reflector length \\
Wa1 & $\mathrm{La} 1 / 10$ & Aperture 1 width \\
Wa2 & $\mathrm{La2} / 10$ & Aperture 2 width \\
Wp & $\mathrm{Lp} / \mathrm{Kp}$ & Patch width \\
Wsr & $\mathrm{Lsr} / \mathrm{K} 1$ & Small reflector width \\
W1 & 3.8 & Ring width \\
\hline
\end{tabular}

Table 3. Electrical parameters of the antenna

\begin{tabular}{llll}
\hline Impedance bandwidth & & Central frequency $f_{0} \mathrm{AR}$ & $11.79 \mathrm{GHz}$ \\
Minimum frequency $f_{\min }$ & $11.41 \mathrm{GHz}$ & Frequency bandwidth BWAR & $0.35 \mathrm{GHz}$ \\
Maximum frequency $f_{\max }$ & $12.24 \mathrm{GHz}$ & Relative bandwidth bw $\mathrm{AR}_{\mathrm{A}} \%$ & $2.96 \%$ \\
Central frequency $f_{0}$ & $11.82 \mathrm{GHz}$ & $\mathrm{G}_{\min } \mathrm{dBi}$ & $8.38 \mathrm{dBi}$ \\
Relative bandwidth bw, $\%$ & $7.02 \%$ & $\mathrm{G}_{\max } \mathrm{dBi}$ & $9.79 \mathrm{dBi}$ \\
Frequency bandwidth $B W$ & $0.83 \mathrm{GHz}$ & $\mathrm{BR}_{\min } \mathrm{dB}$ & $-16.37 \mathrm{~dB}$ \\
Axial Ratio bandwidth & & $\mathrm{BR}_{\max } \mathrm{dB}$ & $-21.23 \mathrm{~dB}$ \\
Minimum frequency $f_{\min } \mathrm{AR}$ & $11.62 \mathrm{GHz}$ & Efficiency $\eta_{\max }$ & $91.62 \%$ \\
Maximum frequency $f_{\max } \mathrm{AR}$ & $11.97 \mathrm{GHz}$ & Directivity $\mathrm{D}_{\max } \mathrm{dBi}$ & $10.17 \mathrm{dBi}$ \\
\hline
\end{tabular}




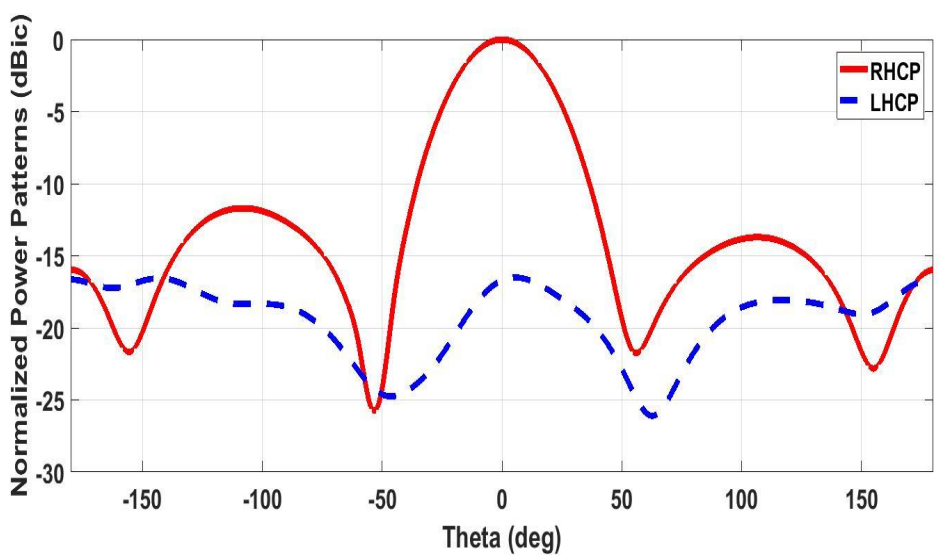

(a)

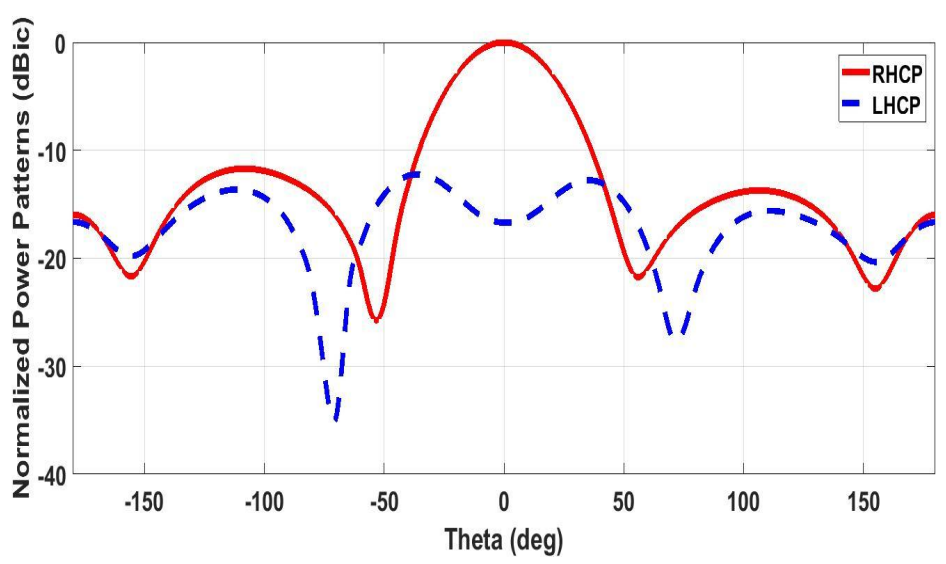

(b)

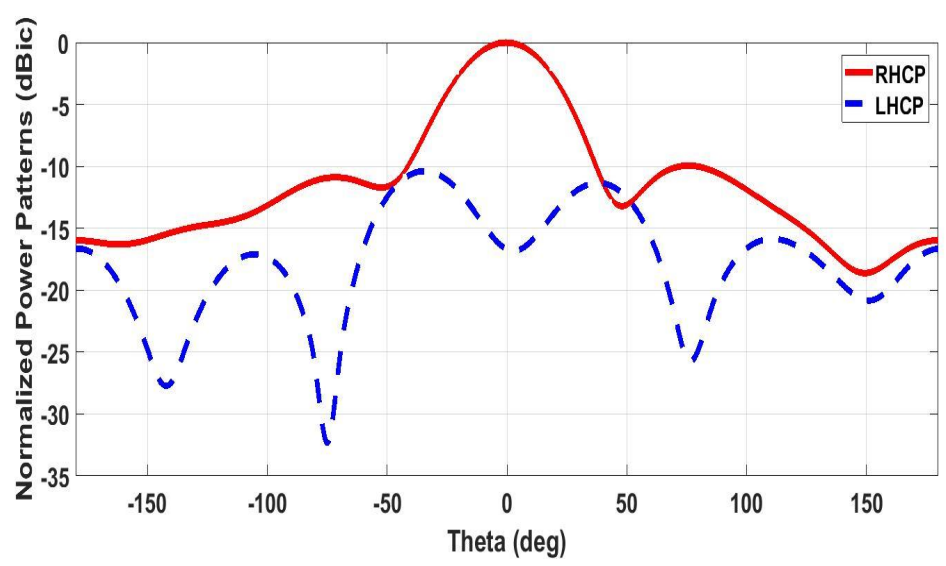

(c)

Fig. 2. Radiation pattern of the antenna at frequency $11.62 \mathrm{GHz}$, (a) $\varphi=0$ degree, (b) $\varphi=45$ degree, (c) $\varphi=90$ degree, RHCP with red line and LHCP with blue dashed

Fig. 3.a, $\mathrm{b}$ and $\mathrm{c}$ shows the radiation pattern at frequency $11.79 \mathrm{GHz}, \varphi=0, \varphi=45$ and $\varphi=90$ degree RHCP with red line and LHCP with blue dashed. 
Fig. 4.a, $\mathrm{b}$ and $\mathrm{c}$ shows the radiation pattern at frequency $11.97 \mathrm{GHz}, \varphi=0, \varphi=45$ and $\varphi=90$ degree. RHCP with red line and LHCP with blue dashed.

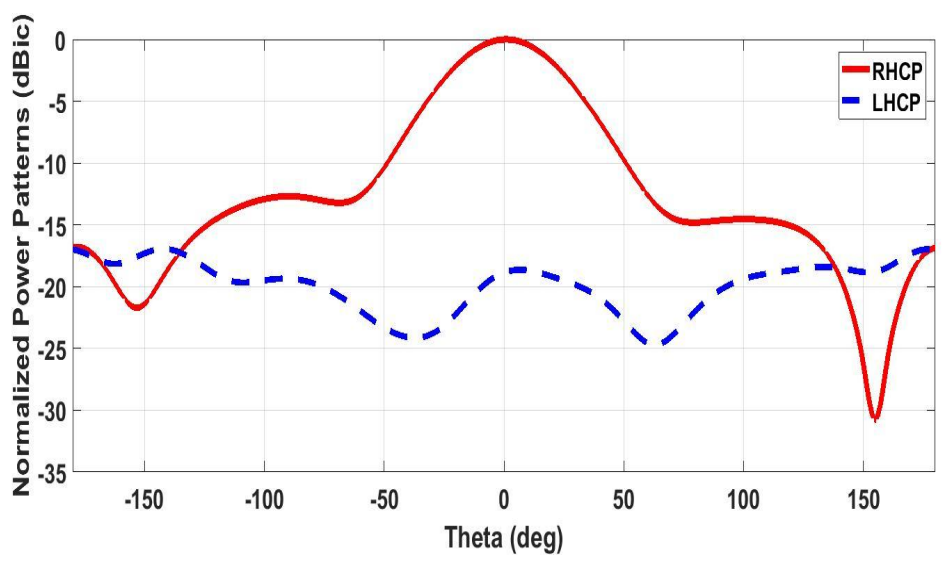

(a)

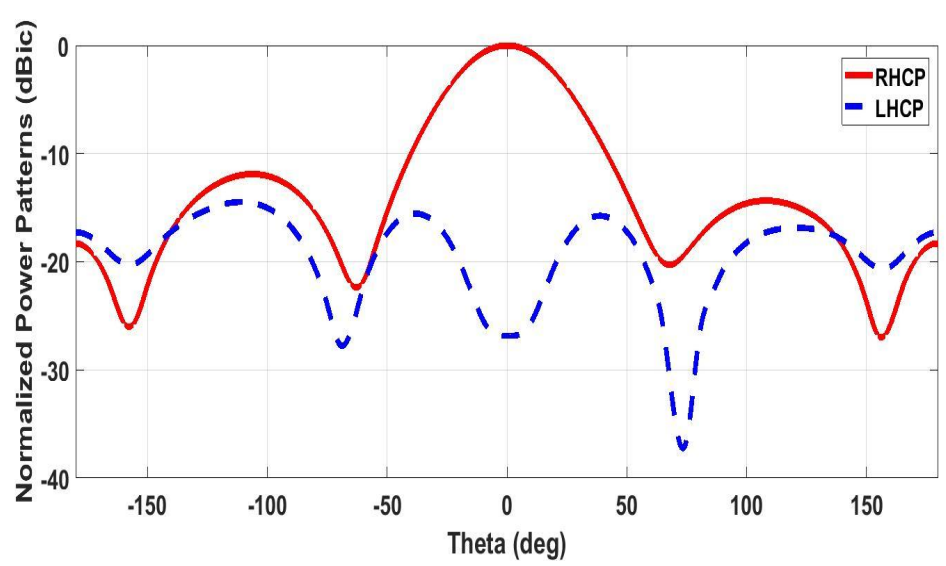

(b)

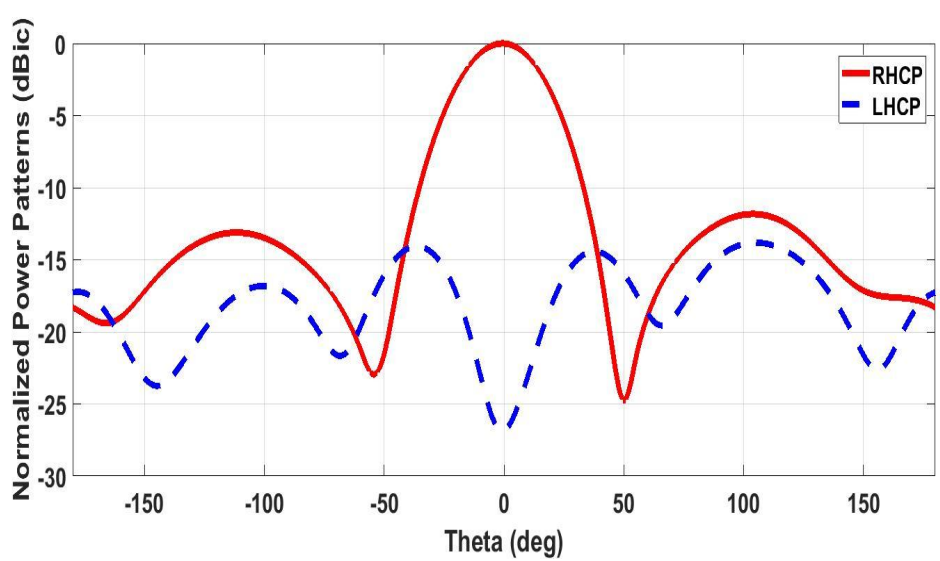

(c)

Fig. 3. Radiation pattern of the antenna at frequency $11.79 \mathrm{GHz}$, (a) $\varphi=0$ degree, (b) $\varphi=45$ degree, (c) $\varphi=90$ degree, RHCP with red line and LHCP with blue dashed 


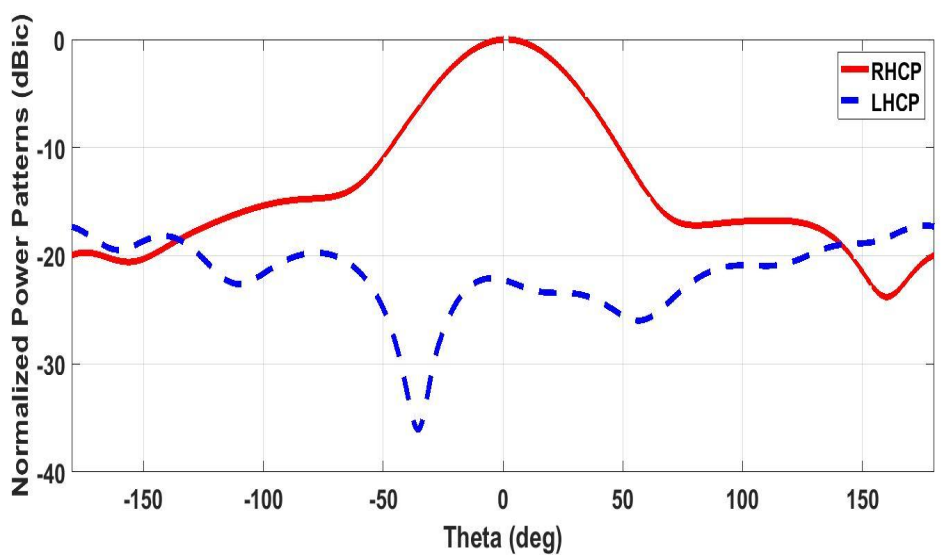

(a)

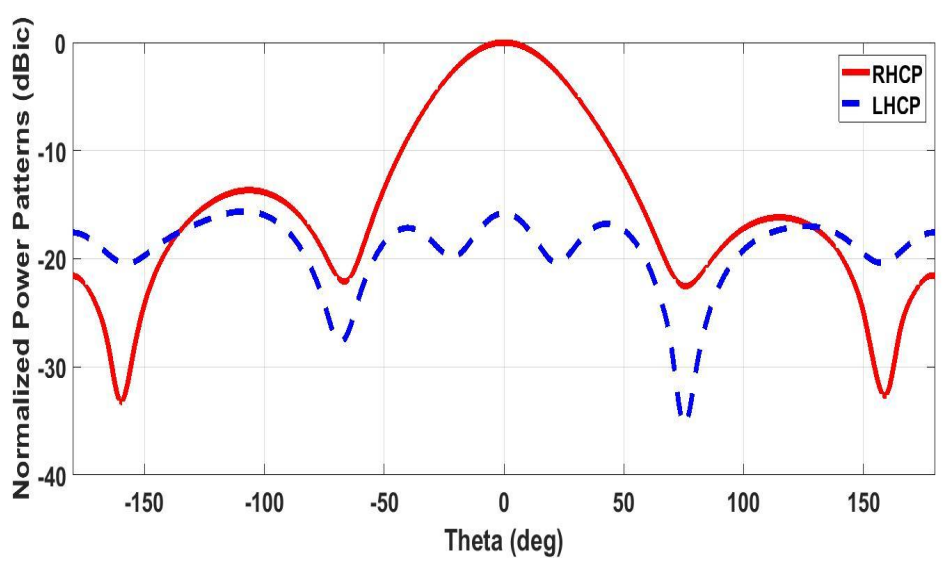

(b)

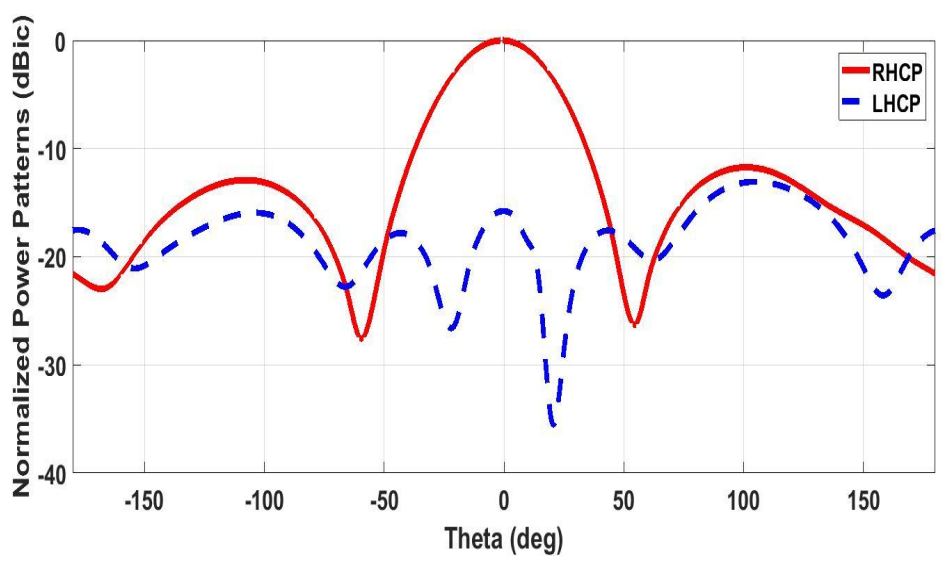

(c)

Fig. 4. Radiation pattern of the antenna at frequency $11.97 \mathrm{GHz}$, (a) $\varphi=0$ degree, (b) $\varphi=45$ degree, (c) $\varphi=90$ degree, RHCP with red line and LHCP with blue dashed

Fig. 5. Shows comparisons of the copolarizations (RHCP) at frequency $11.79 \mathrm{GHz}, \varphi$ $=45$ degree with two different software's CST
MWS 2010 and HFSS, the both curves for RHCP have similar behaviors which indicated a good agreement of the obtained simulated results. 


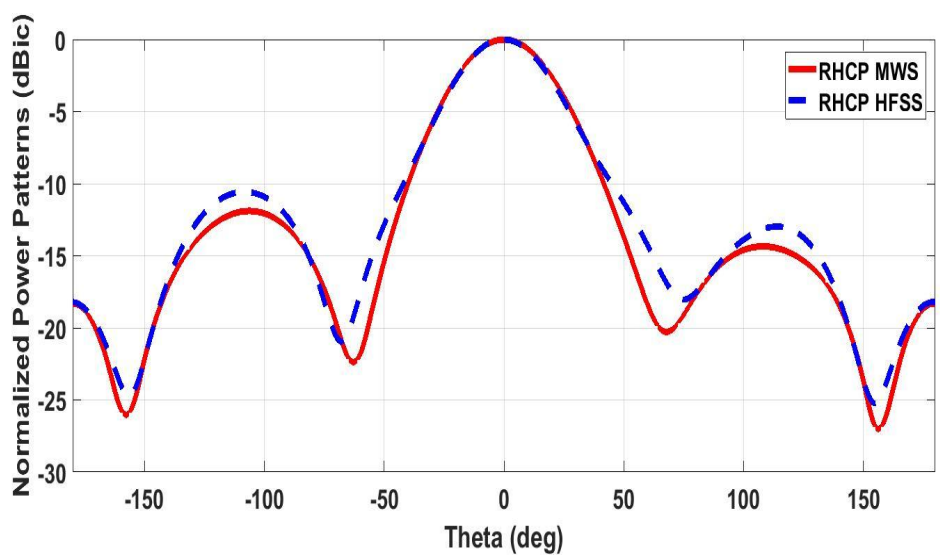

Fig. 5. Co-polarization (RHCP) of the antenna at frequency $11.79 \mathrm{GHz}, \varphi=45$ degree, MWS red line, HFSS blue dashed

\section{DISCUSSION RESULTS}

In this study an aperture coupled microstrip short backfire antenna was designed and investigated. The following features of the proposed antenna design need discussion.

\subsection{Advantage of the Antenna}

The impedance bandwidth of the CP antenna bws $_{11}$ is $7 \%$ while its polarization bandwidth bw is equal to $2.96 \%$, this is good bw bR $_{\text {R }}$ bandwidth compared with the conventional microstrip antenna. The bandwidth enhancement in this case is due to the type of chosen feed, suitable choice of the values of substrate dielectric constants, thickness, optimization of antenna dimension and insertion of two resonances in the antenna impedance characteristics. The first of these resonance (the patch resonances) is at lower frequency while the second resonance (the backfire resonance) is at higher frequency.

The CP antenna gain ranges from $8.38 \mathrm{dBic}$ to $9.79 \mathrm{dBic}$ within the antenna bandwidth, at the central frequency $f_{0}=11.795 \mathrm{GHz}$, the antenna has gain $\mathrm{G}_{0}=9.6 \mathrm{dBic}$, radiation efficiency $\eta_{\text {effo }}$ $=91.2 \%$. The presence of corrugated rim improves the antenna gain by approximately 0.5 dBic compared to the antenna with conventional rim.

The back-radiation level of the $\mathrm{CP}$ antenna varies between $-16 \mathrm{~dB}$ and $-21 \mathrm{~dB}$ across the antenna bandwidth. The basic contribution to this good results is due to the presences of the screen and rim.
The antenna construction is compact, robust and with a low volume. The volume and aperture area of the antenna for example are 3 times less than the corresponding dimensions of the CP SBFA with an air cavity.

\subsection{Disadvantage of the Antenna}

The antenna gain is lower compared to the conventional CP SBFA with an air cavity due to the reduced dimension.

\section{CONCLUSION}

A broadband circularly polarized aperture coupled microstrip short backfire antenna with one ring corrugated rim has been designed and numerically investigated. The bandwidth widening of the antenna is achieved by use of two resonance: a patch resonance and a backfire resonance, it has maximum gain $9.79 \mathrm{dBi}$, maximum back radiation $\mathrm{BR}_{\max }-21.23$, maximum efficiency $91.62 \%$ and axial ratio bandwidth is $2.96 \%$, this is good bandwidth compared with conventional microstrip antenna. The antenna is designed to operate within KU-band. The designed antenna has a simple and compact construction and high mechanical and electrical characteristics; it can be used as a single antenna or as an element of microstrip antenna arrays with various applications, in the various communication systems, including radar, mobile communications, satellite communications and wireless local area networks.

\section{COMPETING INTERESTS}

Author has declared that no competing interests exist. 


\section{REFERENCES}

1. Balanis CA. Antenna theory: Analysis and design. Third Edition, John Wiley \& Sons Inc; 2005.

2. Waterhouse RB. Microstrip patch antenna, a designer guide. Kluwer Academic Publishers; 2003.

3. Bahl IJ; Bhartia P. Microstrip Antennas, Dedham MA. Artech House; 1980.

4. Vivek SK, Geetam ST. Size reduction of microstrip patch antenna using defected microstrip structures. International Conference on Communication Systems and Network Technologies.

5. Volakis JL. Antenna engineering handbook, 4 Edition Chapters. 7.1; 2007.

6. Iwasaki H. A circularly polarized small-size microstrip antenna with a cross slot, IEEE Trans. Antennas Propag. 1996;44(10): 1399-140.

7. Huang $\mathrm{CY}, \mathrm{Wu} \mathrm{JY}$, et al. Cross-slotcoupled microstrip antenna and dielectric resonator antenna for circular polarization, IEEE Trans. Antennas Propag.1999;47(4): 605-609.
8. Al-Jibouri BH, Evans $\mathrm{K}$, et al. Cavity model of circularly polarized cross-aperturecoupled microstrip antenna, Pro. IEE Microwave, Antennas \& Wave Propag. 2001;148(3):147-152.

9. Sievenpiper D, Hsu HP, et al. Low-profile cavity backed crossed-slot antenna with a single- probe feed designed for 2.34- $\mathrm{GHz}$ satellite radio applications, IEEE Trans. Antennas Propag. 2004;52(3):873-879.

10. Pozar DM, Schaubert DH. The analysis and design of microstrip antennas and arrays, University of Massachusetts at Amherst, A selected Reprint Volume, IEEE Antennas and propagation Society, Sponsor the Institute of Electrical and Electronics Engineers, Inc. New York; 17.

11. Tragonski SD, Pozar DM. Design of wideband circularly polarized aperturecoupled microstrip antennas. IEEE, Transactions Antennas and Propagation. 1993;41(2).

12. Abdoula K. Circularly polarized aperture coupled microstrip short backfire antenna with one Rings. International Journal of Computer Science (IIJCS), India, Online. 2017;5(5):01-12. (ISSN: 2321-5992)

(c) 2017 Abdoula; This is an Open Access article distributed under the terms of the Creative Commons Attribution License (http://creativecommons.org/licenses/by/4.0), which permits unrestricted use, distribution, and reproduction in any medium, provided the original work is properly cited.

Peer-review history:

The peer review history for this paper can be accessed here: http://sciencedomain.org/review-history/19814 